\title{
Amperometric D-Gluconate Sensor Using D-Gluconate Dehydrogenase from Bacterial Membranes
}

\author{
Tokuji Ikeda, Koujiro Miki, Fumiyoshi Fushimi \\ and Mitsugi SENDA \\ Department of Agricultural Chemistry, Fuculty of Agriculture, \\ Kyoto University, Kyoto 606, Japan
}

Received January 13, 1988

\begin{abstract}
D-Gluconate dehydrogenase (EC 1.1.99.3) from bacterial membranes was immobilized on the surface of a carbon paste electrode with mixed-in $p$-benzoquinone. The electrode surface was covered with a dialysis membrane. The current response to D-gluconate of electrodes with different amounts of the immobilized enzyme and different thicknesses of the dialysis membrane was studied, and their effects on the current response were quantitatively evaluated by the theory of biocatalyst electrodes with an entrapped mediator. On this basis, an electrode suited for a D-gluconate sensor was constructed and the current-response characteristics of the electrode (reponse time, linear range of the calibration curve, influences of $\mathrm{pH}$, temperature, oxygen and so on) were investigated. The amperometric D-gluconate sensor required neither oxygen nor any reagents to be added to the test solution, and could measure D-gluconate in the range of 0.1 to $4 \mathrm{~mm}$.
\end{abstract}

The importance of developing an analytical method specific to D-gluconate, GlcA, is well recognized because of its widespread use in the food, metal, textile and cement industries. ${ }^{1,2)}$ Enzymatic $^{3)}$ and nonenzymatic methods ${ }^{2)}$ have been reported for the determination of GlcA, enzymatic methods generally being more specific than nonenzymatic methods, and a kit for enzymatic analysis of GlcA in foodstuffs is commercially available. ${ }^{4)}$ The enzymatic method is based on a gluconate kinase reaction coupled with 6-phosphogluconate dehydrogenase in the presence of ATP and $\mathrm{NADP}^{+}$; the increase in the absorbance at $340 \mathrm{~nm}$ due to NADPH is measured. An attempt to construct a GlcA sensor has been reported by Jansen and Rechnitz. ${ }^{5}$ They immobilized gluconate kinase and 6-phosphogluconate dehydrogenase at the surface of a $\mathrm{CO}_{2}$ electrode; the $\mathrm{CO}_{2}$ produced by the sequence of the enzyme reactions in the presence of ATP and $\mathrm{NADP}^{+}$in the test solution was potentiometrically measured. Ameyama et $a l^{3}{ }^{3}$ have developed a new enzymatic method which is highly specific to D-gluconate. They used D-gluconate dehydrogenase (GADH, EC 1.1.99.3) from bacterial membranes and ferricyanide as an electron acceptor; ferrocyanide produced by the enzyme reaction was determined colorimetrically using ferric-Dupanol reagent. We have shown ${ }^{6}$ that GADH can be immobilized on the surface of a carbon paste electrode with mixed-in ubiquinone, and that the GADH-modified carbon paste electrode with mixed-in ubiquinone shows a current response to GlcA due to the ubiquinonemediated electrocatalytic oxidation of GlcA. $p$-Benzoquinone (BQ) also served as the mediator in place of ubiquinone. ${ }^{6)}$ In this paper, we describe a use of the DADHmodified carbon paste electrode as an amperometric GlcA sensor, in which BQ is used as the mediator because it is readily available and less expensive than ubiquinone.

\section{EXPERIMENTAL}

Enzyme preparation. Preparation of a solution of partially purified GADH (ED 1.1.99.3) from Pseudomonas fluorescens $\mathrm{FM}-1^{7)}$ was done as previously described ${ }^{67}$ The 
GADH solution contained $2.8 \mathrm{~g} / \mathrm{dm}^{3}$ protein, $1 \%$ sodium cholate, and $10 \mathrm{mmol} / \mathrm{dm}^{3}$ phosphate buffer ( $\mathrm{pH} 6.0$ ). The enzyme activity of the GADH solution was 9.0 units $/ \mathrm{cm}^{3}$ when assayed by the method described in ref. 6 . The $\mathrm{GADH}$ solution could be stored at $-20^{\circ} \mathrm{C}$ for more than two years with a small loss of the enzyme activity (7.0 units $/ \mathrm{cm}^{3}$ after two years).

Electrode construction. A carbon paste electrode with mixed-in BQ was prepared as described elsewhere, ${ }^{89}$ ) the geometrical surface area of the electrode being $0.09 \mathrm{~cm}^{2}$. This carbon paste electrode with mixed-in $\mathrm{BQ}$ was dipped into the GADH solution and kept there for $10 \mathrm{~min}$, during which time GADH was adsorbed irreversibly onto the electrode surface. Then, the electrode was rinsed with an acetate buffer solution of $\mathrm{pH} 4.5$. In this way, a thin layer of immobilized GADH (estimated as $1 \pm 0.1 \mu \mathrm{g} / \mathrm{cm}^{2}$ ) could be formed on the surface of the carbon paste electrode. ${ }^{6)}$ This GADH-modified electrode is referred to as a GADH-BQ CPE in this paper. To immobilize larger amounts of GADH, 5 to $20 \mu \mathrm{l}$ portions of the GADH solution were syringed onto the surface of carbon paste electrodes with mixed-in BQ and the solvent was allowed to evaporate. Then, the electrodes were covered with dialysis membranes ( $c f$. Fig. 4 in ref. 10 for the electrode construction). The GADH-modified electrode with the dialysis membrane is referred to here as a film-coated GADH-BQ CPE.

Electrochemical measurements. Electrochemical measurements were done at $25 \pm 0.1^{\circ} \mathrm{C}$ in a $0.1 \mathrm{M}$ acetate buffer solution of $\mathrm{pH} 4.5$ (the basal buffer solution) stirred at $500 \mathrm{rpm}$ with a magnetic stirrer, unless otherwise stated. All potentials were measured against a saturated calomel electrode (SCE).

Reagent and apparatus have been previously described. ${ }^{6,8,9}$

\section{RESULTS AND DISCUSSION}

\section{Amperometric response of $G A D H-B Q C P E s$}

Previous experiments with GADH-modified carbon paste electrodes with mixed-in ubiquinone or BQ showed ${ }^{6}$ that these quinones in the carbon paste dissolved into the enzyme layer on the electrode surface to reach a steady-state concentration there. Thus, the GADH-modified electrode with mixed-in BQ immersed in a buffer solution produced cyclic voltammetric waves due to the electrochemical redox reaction of BQ in the enzyme layer. Such cyclic voltammetric waves are shown in Fig. 1A. When sodium D-gluconate (GlcA) was added to the solution, the anodic current

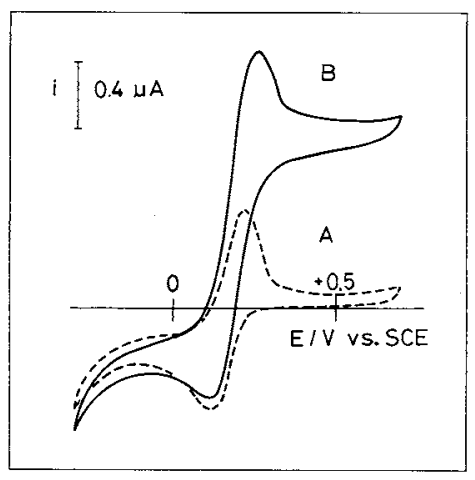

FiG. 1. Cyclic Voltammograms of a GADH-BQ(0.26\%) $\mathrm{CPE}$ in (A) $0.1 \mathrm{M}$ Acetate Buffer at $\mathrm{pH} 4.5$ (the Basal Buffer Solution) and (B) A Plus $50 \mathrm{~mm}$ D-Gluconate.

The potential scan rate was $1 \mathrm{mV} / \mathrm{sec}$.

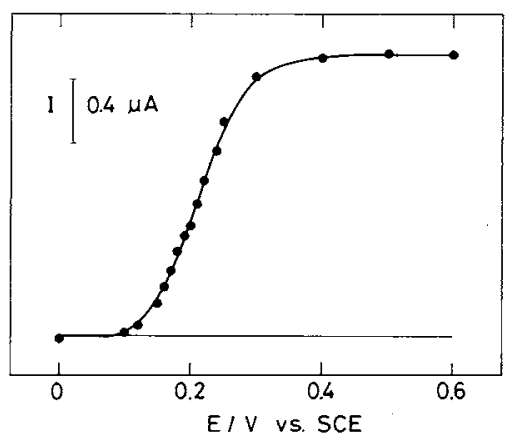

FIG. 2. Dependence of the Steady-state Anodic Current, I, on the Potential Applied to a GADH-BQ $(0.65 \%)$ CPE. I was measured in the basal buffer solution containing $50 \mathrm{~mm}$ GlcA.

increased greatly as shown in Fig. 1B, the increase in this anodic current being due to the BQ-mediated electrocatalytic oxidation of GlcA. ${ }^{6)}$ The anodic current in the steady-state, $I$, was obtained when measured at a fixed electrode potential, $E$. I started to appear at $+0.1 \mathrm{~V}$ and incresed with increasing positive potential to reach a limiting current at $E>0.3 \mathrm{~V}$ (Fig. 2), where $I$ was measured with a GADH-BQ $\left(m_{\mathrm{BQ}}=0.65 \% \mathrm{w} / \mathrm{w}\right) \mathrm{CPE}$ in a $0.1 \mathrm{M}$ acetate buffer of $\mathrm{pH} 4.5$ (the basal buffer solution) containing $50 \mathrm{~mm}$ GlcA, $m_{\mathrm{BQ}}$ being the amount of $\mathrm{BQ}$ mixed in the carbon paste. In the subsequent experiments, we measured the limiting anodic current, $I_{l}$, at $+0.4 \mathrm{~V}$.

We have shown ${ }^{9 \sim 11)}$ that the limiting anodic 


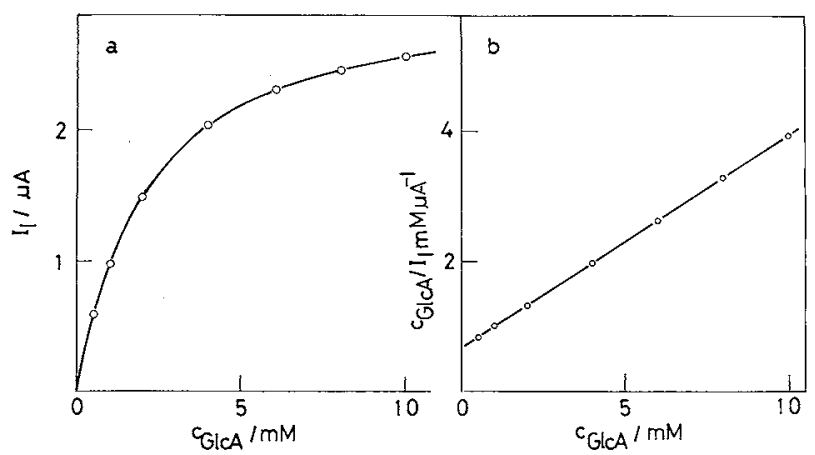

FIG. 3. a: Dependence of the Limiting Anodic Current at $+0.4 \mathrm{~V}, I_{l}$, on the Concentration of GlcA, $\dot{c}_{\text {GlcA }}$. $I_{l}$ was measured with a GADH-BQ $(1.3 \%) \mathrm{CPE}$ in the basal buffer solution containing GlcA.

b: Plot of $c_{\mathrm{GlcA}} / I_{t}$ against $c_{\mathrm{GlcA}}$.

current due to mediator-assisted bioelectrocatalysis can be expressed by

$$
I_{l}=I^{\max ^{\prime}} /\left(1+\left(K_{\mathrm{m} 2}^{\prime} / c_{\mathrm{M}}\right)+\left(K_{\mathrm{m} 1}^{\prime} / \beta_{\mathrm{s}}^{\circ} c_{\mathrm{s}}\right)\right)
$$

where $I^{\max ^{\prime}}$ is the apparent maximum current, $K_{\mathrm{m} 1}^{\prime}$ and $K_{\mathrm{m} 2}^{\prime}$ the apparent Michaelis constants for the substrate (here GlcA) and the mediator (here $\mathrm{BQ}$ ), respectively, $\beta_{\mathrm{s}}$ the distribution coefficient of the substrate between the enzyme layer and the solution, $c_{\mathrm{M}}$ the concentration of the mediator in the enzyme layer, and ${ }^{\circ} c_{\mathrm{s}}$ the concentration of the substrate at the surface of the electrode in the solution. The apparent constants, $I^{\max ^{\prime}}, K_{\mathrm{m} 1}^{\prime}$ and $K_{\mathrm{m} 2}^{\prime}$, generally include the effect of the concentration polarization of the substrate and mediator in the enzyme layer. In GADH-BQ CPEs, however, the enzyme layer is so thin that the effect of the concentration polarization is small ${ }^{6}$; therefore the apparent constants, $I^{\text {max }}, K_{\mathrm{m} 1}^{\prime}$ and $K_{\mathrm{m} 2}^{\prime}$ may be equated to their true constants, $I^{\max }$, $K_{\mathrm{m} 1}$ and $K_{\mathrm{m} 2}$, respectively. $c_{\mathrm{M}}$ has been found to be proportional to $m_{\mathrm{BQ}},{ }^{6)}$ and ${ }^{\circ} \mathcal{C}_{\mathrm{s}}$ can be equated to the bulk concentration of GlcA, $c_{\mathrm{GlcA}}$, under the present experimental conditions, where the concentration polarization of GlcA in solution appeared to be negligibly small. As expected from Eq. (1), $I_{l}$ measured with a GADH-BQ CPE increased with increasing $m_{\mathrm{BQ}}\left(c_{\mathrm{M}}\right.$ being proportional to $\left.m_{\mathrm{BQ}}\right)$ and approached a saturation value at $m_{\mathrm{BQ}}>1.3 \%$, indicating that $K_{\mathrm{m} 2}^{\prime} / c_{\mathrm{M}} \ll 1$ at $m_{\mathrm{BQ}}>1.3 \% . I_{l}$ also increased with increasing $c_{\text {GleA }}$ to approach a saturation value. The result obtained with a GADH-BQ $(1.3 \%) \mathrm{CPE}$ is shown in Fig. 3a; the plot of $c_{\mathrm{GlcA}} / I_{l}$ against $c_{\text {GleA }}$ gave a straight line as shown in Fig. $3 b$. In this case Eq. (1) can be simplified to

$$
I_{l}=I^{\max ^{\prime}} /\left(\mathrm{I}+\left(K_{\mathrm{m} 1}^{\prime} / \beta_{\mathrm{s}} c_{\mathrm{GlcA}}\right)\right)
$$

The $I^{\max ^{\prime}}$ and $K_{\mathrm{m} 1}^{\prime} / \beta_{\mathrm{s}}$ values, which may be equated to the $I^{\max }$ and $K_{\mathrm{m} 1} / \beta_{\mathrm{s}}$ values, can be calculated from the slope and intercept of the plot in Fig. $3 \mathrm{~b}$ to be $3.1 \mu \mathrm{A}$ and $2.1 \mathrm{~mm}$, respectively.

\section{Amperometric response of film-coated $G A D H$ -} $B Q(1.3 \%)$ CPES

We prepared film-coated GADH-BQ $(1.3 \%)$ CPEs of different film thicknesses and different amounts of immobilized GADH, and investigated their effect on the current response. Figure 4 shows the dependence of $I_{l}$ on $c_{\text {GlcA }}$ obtained with three different film-coated GADH-BQ $(1.3 \%)$ CPEs in the basal solution containing GlcA. The electrodes were prepared by the application of $20 \mu$ of the GADH solution and were covered with dialysis membranes of thicknesses (A) 20, (B) 40, and (C) $60 \mu \mathrm{m}$. The linear range of the $I_{l} v s . c_{\mathrm{GIcA}}$ plots extended to a higher concentration of GlcA than that obtained with the GADH-BQ $(1.3 \%)$ CPE (Fig. 3). The slope of the plots decreased with increasing thickness of the membrane coating the electrode surface. The results indicate that the diffusion rate of GlcA through 


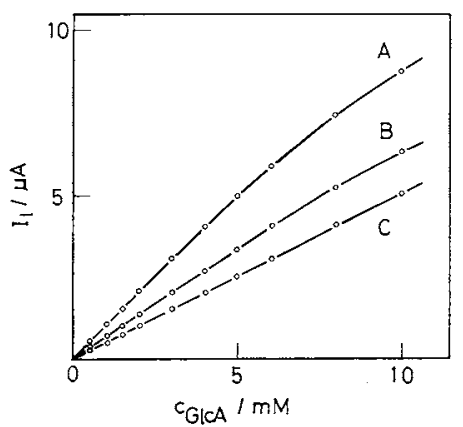

FiG. 4. Dependence of $I_{l}$ on $c_{\mathrm{GleA}}$

$I_{l}$ was measured with film-coated GADH-BQ(1.3\%) CPEs in the basal buffer solution containing GlcA. The thickness of the dialysis membrane of the electrodes, $l_{\mathrm{m}}$, was (A) 20 , (B) 40 and (C) $60 \mu \mathrm{m}$.

the dialysis membrane had an effect. Taking into account this diffusional process in the dialysis membrane, we have ${ }^{9,10)}$

$$
\begin{gathered}
I_{l}=I^{\max ^{\prime}} /\left(1+K_{\mathrm{m} 1}^{\prime} /\left(\beta_{\mathrm{s}} c_{\mathrm{GlcA}}\right.\right. \\
\left.\left.-\left(\beta_{\mathrm{s}} I_{l} / n F A P_{\mathrm{sm}}\right)\right)\right)
\end{gathered}
$$

where $n, F$ and $A$ are the number of electrons (here $n=2$ ), the Faraday constant and the electrode surface area, respectively, and $P_{\mathrm{sm}}$ the permeability of the dialysis membrane to GlcA. $P_{\text {sm }}$ is defined by

$$
P_{\mathrm{sm}}=\beta_{\mathrm{sm}} D_{\mathrm{sm}} / l_{\mathrm{m}}
$$

Here $\beta_{\mathrm{sm}}$ is the distribution coefficient of GlcA between the dialysis membrane and the solution, $D_{\mathrm{sm}}$ the diffusion coefficient of GlcA in the dialysis membrane, and $l_{\mathrm{m}}$ the thickness of the dialysis membrane. In Eq. (2), the quantity,

$$
\beta_{\mathrm{s}} c_{\mathrm{GIcA}}-\left(\beta_{\mathrm{s}} I_{l} / n F A P_{\mathrm{sm}}\right),
$$

represents the concentration of GlcA in the enzyme layer at the enzyme layer-dialysis membrane interface. When $c_{\mathrm{GlcA}}$ is low enough to satisfy the condition that

$$
\begin{aligned}
&\left(c_{\mathrm{GlcA}} \beta_{\mathrm{s}} / K_{\mathrm{m} 1}^{\prime}\right)-\left(I_{t} \beta_{\mathrm{s}} / n F A P_{\mathrm{sm}} K_{\mathrm{m} 1}^{\prime}\right) \\
& \ll 1+\left(I^{\max } \beta_{\mathrm{s}} / n F A P_{\mathrm{sm}} K_{\mathrm{m} 1}^{\prime}\right),
\end{aligned}
$$

Eq. (2) is reduced to ${ }^{9,10)}$

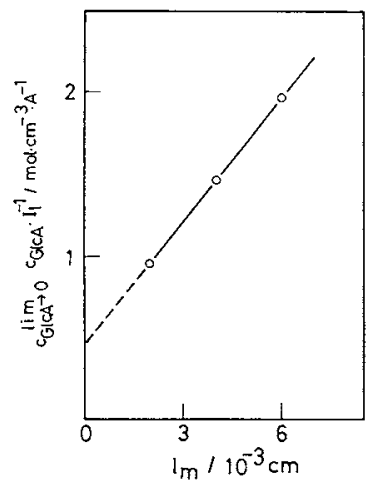

FIG. 5. Dependence on $l_{\mathrm{m}}$ of the Values of the Intercept at $c_{\mathrm{GlcA}} \rightarrow 0$ of $c_{\mathrm{GlcA}} / I_{l} v s . c_{\mathrm{GlcA}}$ Plots of the Data in Fig. 4.

$$
\begin{aligned}
I_{1}= & n F A P_{\mathrm{sm}} c_{\mathrm{GlcA}} / \\
& \left(1+\left(n F A P_{\mathrm{sm}} K_{\mathrm{m} 1}^{\prime} / \beta_{\mathrm{s}} I^{\mathrm{max}^{\prime}}\right)\right)
\end{aligned}
$$

This equation explains the initial slope of the $I_{l}$ vs. $c_{\mathrm{GlcA}}$ plots in Fig. 4 ; the smaller $P_{\mathrm{sm}}$, that is, the larger $l_{\mathrm{m}}$ results in the smaller slope. If we plot $c_{\mathrm{GlcA}} / I_{l}$ against $c_{\mathrm{GlcA}}$, the intercept of the plot at $c_{\mathrm{GlcA}} \rightarrow 0$ gives

$$
\begin{aligned}
c_{\mathrm{GlcA}} / & I_{l}\left(c_{\mathrm{GlcA}} \rightarrow 0\right) \\
= & 1 / n F A P_{\mathrm{sm}}\left(=l_{\mathrm{m}} / n F A \beta_{\mathrm{sm}} D_{\mathrm{sm}}\right) \\
& +K_{\mathrm{m} 1}^{\prime} / \beta_{\mathrm{s}} I^{\max }
\end{aligned}
$$

The values of the intercept for electrodes A, B and $\mathrm{C}$ were obtained by replotting the data in Fig. 4 as $c_{\text {GlcA }} / I_{l}$ vs. $c_{\text {GleA }}$ plots, and these are plotted against $l_{\mathrm{m}}$ in Fig. 5. The plot is linear as predicted by Eq. (4). From the slope of this plot, $\beta_{\mathrm{sm}} D_{\mathrm{sm}}$ can be calculated to be $2.3 \times 10^{-7}$ $\mathrm{cm}^{2} / \mathrm{sec}$, which leads to the $P_{\mathrm{sm}}$ value of $1.2 \times 10^{-4} \mathrm{~cm} / \mathrm{sec}$ at $l_{\mathrm{m}}=20 \mu \mathrm{m}$.

Film $(20 \mu \mathrm{m})$-coated GADH-BQ $(1.3 \%)$ CPEs were prepared by the application of $5 \mu \mathrm{l}$ (electrode A), $10 \mu \mathrm{l}$ (electrode B) and $20 \mu \mathrm{l}$ (electrode C) of the GADH solution to the electrode surface. The amounts of immobilized protein were calculated to be 155,310 , and $620 \mu \mathrm{g} / \mathrm{cm}^{2}$ for electrodes $\mathrm{A}, \mathrm{B}$, and $\mathrm{C}$, respectively, from the protein content of the GADH solution $\left(2.8 \mathrm{~g} / \mathrm{dm}^{3}\right)$. These values are much larger than that of the GADH-BQ $(1.3 \%) \mathrm{CPE}\left(1 \mu \mathrm{g} / \mathrm{cm}^{2}\right)$. If we assume that the density of the protein was $1.3 \mathrm{~g} / \mathrm{cm}^{3},{ }^{6}$ ) the 
thickness of the enzyme layer for electrodes A, $\mathrm{B}$ and $\mathrm{C}$ can be estimated to be 1.2, 2.4 and $4.8 \mu \mathrm{m}$, respectively, which are of a comparable order of magnitude to the thickness of the dialysis membrane $(20 \mu \mathrm{m})$ covering the enzyme layer. Consequently, the effect of the diffusional resistance of the enzyme layer, that is, the effect of the concentration polarization of GlcA in the enzyme layer, is presumed to have been large for these electrodes. This effect can be evaluated by the $I^{\max ^{\prime}}$ and $K_{\mathrm{m} 1}^{\prime}$ values in Eqis. (2), (2') and (4) on the first approximation. More rigorously, however, the effect of the diffusional process in the enzyme layer can be expressed ${ }^{10,11}$ by the Thiele modulus $\sigma_{\mathrm{s}}$. Thus, for example, Eq. (4) can be rewritten in dimensionless form as

$$
\begin{aligned}
& \left(c_{\mathrm{GlcA}} \beta_{\mathrm{s}} / K_{\mathrm{m} 1}\right) /\left(I_{l} / I^{\mathrm{max}}\right) \\
& \quad=I^{\max } \beta_{\mathrm{s}} / n F A P_{\mathrm{sm}} K_{\mathrm{m} 1}+\sigma_{\mathrm{s}} / \tanh \sigma_{\mathrm{s}}
\end{aligned}
$$

The parameter $\sigma_{\mathrm{s}}$ is defined by

$$
\sigma_{\mathrm{s}}^{2}=k_{\mathrm{cat}}(E) l^{2} / K_{\mathrm{m} 1} D_{\mathrm{s}}=\left(I^{\mathrm{max}} / n F A K_{\mathrm{m} 1}\right) /\left(D_{\mathrm{s}} / l\right),
$$

where $k_{\text {cat }}$ is the catalytic constant of the GADH reaction, $(E)$ the volume concentration of the immobilized $\mathrm{GADH}, l$ the thickness of the immobilized GADH layer, and $D_{\mathrm{s}}$ the diffusion coefficient of GlcA in the enzyme layer. Figure $6 \mathrm{a}$ shows the dependences of $I_{l} / I^{\max }$ on $c_{\mathrm{GlcA}} /\left(K_{\mathrm{m} 1} / \beta_{\mathrm{s}}\right)$ obtained with electrodes $\mathrm{A}, \mathrm{B}$ and $\mathrm{C}$. The $I^{\max }$ values were obtained from the intercepts at $1 / c_{\mathrm{GlcA}} \rightarrow 0$ of the double reciprocal plots (equivalent to the Lineweaver Burk plot in enzyme kinetics) of the experimental data for $I_{l}$ at various $c_{\mathrm{GlcA}}$. They were $3.5,6.7$ and $19.6 \mu \mathrm{A}$ for electrodes $\mathrm{A}, \mathrm{B}$ and $\mathrm{C}$, respectively. The $K_{\mathrm{m} 1} / \beta_{\mathrm{s}}$ value employed was $2.1 \mathrm{~mm}$ obtained above with the GADH-BQ $(1.3 \%)$ CPE. The slope of the $I_{l} / I^{\max }$ vs. $c_{\mathrm{Glc}} \beta_{\mathrm{s}} / K_{\mathrm{m} 1}$ plots decreased with the increasing amount of immobilized enzyme. Figure $6 \mathrm{~b}$ shows the plots of $\left(c_{\mathrm{GlcA}} \beta_{\mathrm{s}} / K_{\mathrm{m} 1}\right) /$ $\left(I_{l} / I^{\mathrm{max}}\right)$ against $c_{\mathrm{GlcA}} \beta_{\mathrm{s}} / K_{\mathrm{m} 1}$. As predicted by the theory of a bicatalyst electrode with an entrapped mediator, ${ }^{11)}$ the plots are not linear, showing the effect of the diffusional resistance of GlcA in the enzyme layer as well as the dialysis membrane. From the extraporated intercepts at $c_{\mathrm{GlcA}} \beta_{\mathrm{s}} / K_{\mathrm{m} 1} \rightarrow 0$ of the plots in Fig. $6 \mathrm{~b}$, the $\sigma_{\mathrm{s}}$ values for electrodes $\mathrm{A}, \mathrm{B}$ and $\mathrm{C}$ were calculated to be $0.2,1.5$ and 5.1 , respectively, by Eq. $\left(4^{\prime}\right)$ where $P_{\mathrm{sm}}=1.2 \times 10^{-4}$ $\mathrm{cm} / \mathrm{sec}, K_{\mathrm{m} 1} / \beta_{\mathrm{s}}=2.1 \mathrm{~mm}$, and $I^{\max }=3.5,6.7$ and $19.6 \mu \mathrm{A}$ for electrodes $\mathrm{A}, \mathrm{B}$ and $\mathrm{C}$, respectively, were used. The $\sigma_{\mathrm{s}}$ values show that the effect of the diffusion of GlcA in the enzyme layer was not particularly large for electrode $\mathrm{A}$, but significant for electrode $\mathrm{C}$. The solid lines in Fig. 6a are the theoretical curves at $P_{\mathrm{sm}}=1.2 \times 10^{-4} \mathrm{~cm} / \mathrm{sec}$, and at $\sigma_{\mathrm{s}}=$ (A) 0.2 , (B) 1.5 and (C) 5.1 calculated by the method described in ref. 11. The curves explain

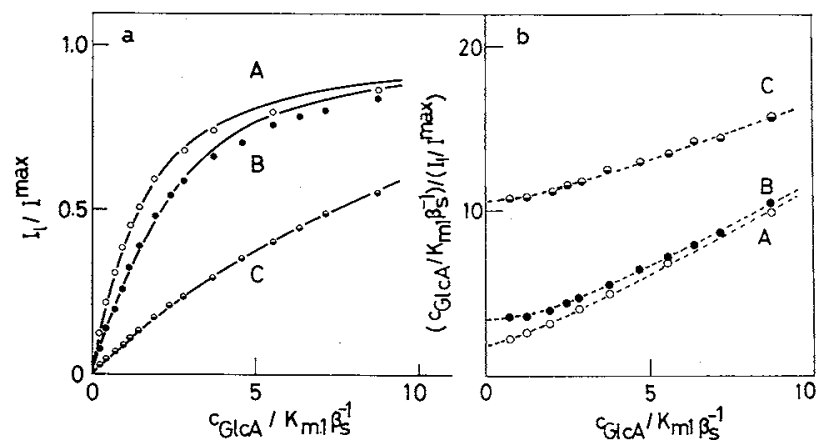

Fig. 6. a: Dependence of $I_{l} / I^{\max }$ on $c_{\mathrm{Gic}} \beta_{\mathrm{s}} / K_{\mathrm{m} 1}$.

$I_{l}$ was measured in the basal buffer solution containing GlcA with film( $(20 \mu \mathrm{m})$-coated GADH-BQ(1.3\% $)$ CPEs prepared by the application of (A) 5 , (B) 10 or (C) $20 \mu \mathrm{l}$ of the GADH solution. $I_{l}$ and $c_{\mathrm{GlcA}}$ were normalized by the $I^{\max }$ and $K_{\mathrm{m} 1} / \beta_{\mathrm{s}}$ values obtained experimentally (see the text). Solid lines are the theoretical curves (see the text).

b: Plots of $\left(c_{\mathrm{GicA}} \beta_{\mathrm{s}} / K_{\mathrm{m} 1}\right)\left(I_{\mathrm{l}} / I^{\mathrm{max}}\right)$ against $c_{\mathrm{GlcA}} \beta_{\mathrm{s}} / K_{\mathrm{m} 1}$. 
well the dependence of $I_{l} / I^{\max }$ on $c_{\mathrm{GlcA}} \beta_{\mathrm{s}} / K_{\mathrm{m} 1}$ obtained experimentally.

\section{Film $(20 \mu \mathrm{m})$-coated GADH-BQ $(1.3 \%)$ CPE as} an amperometric Glc $A$ sensor

The foregoing experimental results show that a film-coated GADH-BQ CPE with a larger $\sigma_{\mathrm{s}}$ and a smaller $P_{\mathrm{sm}}$ produced a linear current response up to a higher concentration of GlcA (Figs. 4 and 6). The current response of the electrode with a smaller $P_{\mathrm{sm}}$ was mainly controlled by the diffusion rate of GlcA in the dialysis membrane, and was almost independent of the rate of the enzyme reaction. ${ }^{10.11)}$ Accordingly, the current response can be expected to be free from the problems inherent in an enzyme reaction such

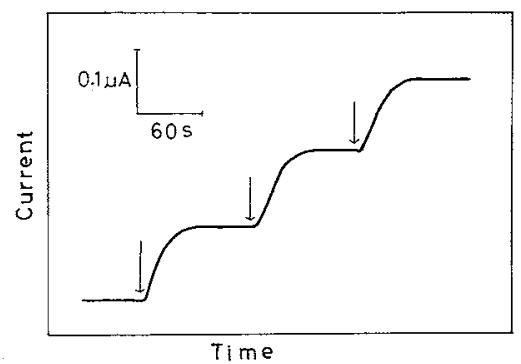

Fig. 7. Typical Current Response of the Film $(20 \mu \mathrm{m})$ coated GADH-BQ $(1.3 \%) \mathrm{CPE}$ to GlcA.

The current was measured at $+0.4 \mathrm{~V} v s$. SCE, and $2 \mu \mathrm{l}$ of $0.2 \mathrm{M}$ GlcA was successively injected (marked by arrows) into $4 \mathrm{ml}$ of the basal buffer solution.

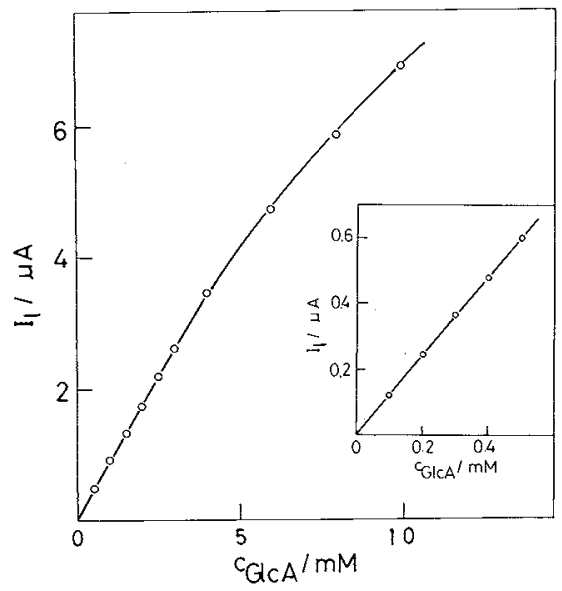

FIG. 8. Calibration Curve for GlcA Obtained with the Film $(20 \mu \mathrm{m})$-coated GADH-BQ(1.3\%) CPE. as a sensitive $\mathrm{pH}$ dependence and a gradual decrease in the sensitivity due to the timedependent loss of enzyme activity. We can easily construct an electrode possessing such properties by using a thicker dialysis membrane, but a thicker membrane concurrently causes reduced sensitivity (Fig. 4) and a prolonged response time. ${ }^{10)}$ Considering these circumstances, we chose an electrode with a dialysis membrane of $20 \mu \mathrm{m}$ thickness covering an immobilized $\mathrm{GADH}$ layer of $620 \mu \mathrm{g} /$ $\mathrm{cm}^{2}$, a film $(20 \mu \mathrm{m})$-coated GADH-BQ $(1.3 \%)$ $\mathrm{CPE}$, as an amperometric GlcA sensor. Figure 7 shows the typical current response to GlcA of the film $(20 \mu \mathrm{m})$-coated GADH-BQ $(1.3 \%)$ CPE. The steady-state current response was reached within $60 \mathrm{sec}$. The dependence of $I_{l}$ on $c_{\mathrm{GlcA}}$ is shown in Fig. 8. $I_{l}$ was proportional to $c_{\mathrm{GIcA}}$ from 0.1 to $4 \mathrm{~mm}$ and deviated downward with a further increase in $c_{\mathrm{GlcA}}$. The effect of the $\mathrm{pH}$ of the test solution on $I_{l}$ was investigated at $c_{\mathrm{GlcA}}=1 \mathrm{~mm}$ between $\mathrm{pH} 3.5$ and 7.5, $I_{l}$ being independent of $\mathrm{pH}$ in the range $3.5<\mathrm{pH}<6.5$, and decreasing slightly at $\mathrm{pH}>6.5$. The effect of temperature on $I_{l}$ was also examined at $c_{\mathrm{GlcA}}=$ $1 \mathrm{~mm}$ in the range between 15 and $35^{\circ} \mathrm{C}$. $I_{l}$ increased with increasing temperature, giving a temperature coefficient of $3 \%$ at $25^{\circ} \mathrm{C}$. The activation energy was calculated to be $21.8 \mathrm{~kJ} / \mathrm{mol}$ from the slope of the $\ln I_{l} v s . T^{-1}$ plot, $T$ being the absolute temperature. All the

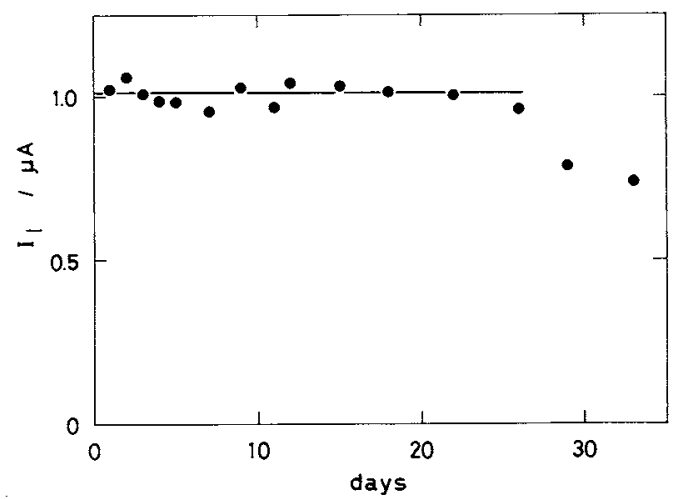

FIG. 9. Long-term Stability of the Film $(20 \mu \mathrm{m})$-coated GADH-BQ $(1.3 \%)$ CPE.

$I_{l}$ was measured at $1 \mathrm{~mm} \mathrm{GlcA}$ in the basal buffer solution. 
results were those expected for an electrode whose current response was mainly controlled by the diffusion rate of GlcA in the dialysis membrane as already revealed. The reproducibility of the current response of the film $(20 \mu \mathrm{m})$-coated GADH-BQ $(1.3 \%) \mathrm{CPE}$ was examined at $c_{\mathrm{GlcA}}=1 \mathrm{mM}$, and the coefficient of variation was determined to be $4.8 \%$ $(n=9)$. The reproducibility of preparing the electrode was tested by measuring $I_{l}$ at $c_{\mathrm{GlcA}}=$ $1 \mathrm{~mm}$ for three different film $(20 \mu \mathrm{m})$-coated GADH-BQ $(1.3 \%)$ CPEs. They gave an average $I_{l}$ of $1.02 \mu \mathrm{A}$ with a standard deviation of $0.15 \mu \mathrm{A}$. When $I_{l}$ was measured in a de-aerated solution, the same magnitude of $I_{l}$ as that measured in an air-saturated solution was obtained within the bounds of experimental error. This result confirms that $I_{l}$ was insensitive to variations of oxygen tension in the test solution. D-Glucose and 2-keto Dgluconate, the product of the GADH reaction, showed no influence on $I_{l}$ at their concentrations of $10 \mathrm{~mm}$, but L-ascorbic acid gave a positive interference current of $0.67 \mu \mathrm{A}$ at the concentration of $0.5 \mathrm{~mm}$. The interference of such substances as $\mathrm{L}$-ascorbic acid, which are directly oxidizable at the electrode, can be eliminated, for example, by placing an electrochemical filter ${ }^{12)}$ in front of the GADHmodified CPE. The stability of the electrode was studied by testing its response to $1 \mathrm{~mm}$ GlcA once a day; the electrode was stored at $5^{\circ} \mathrm{C}$ in a $0.1 \mathrm{M}$ acetate buffer solution at $\mathrm{pH} 4.5$ when not in use. The current response remained unchanged within the bounds of experimental error for almost a month (Fig. 9).

The foregoing results show that the film $(20 \mu \mathrm{m})$-coated GADH-BQ (1.3\%) CPE can be used as an amperometric D-gluconate sensor that provides a linear current response to GlcA from 0.1 to $4 \mathrm{~mm}$. This covers the concentration range usually measured with a kit for enzymatic analysis of GlcA in foodstuffs. ${ }^{4}$ The method using the film $(20 \mu \mathrm{m})$ coated GADH-BQ $(1.3 \%) \mathrm{CPE}$ does not require any reagent to be added to the test solution and is insensitive to oxygen tension in the solution. The method also allows GlcA to be measured in a turbid solution.

Acknowledgments. We are grateful to Professor Ameyama and Professor Adachi of Yamaguchi University for their kind donation of the strain P. fuorescens FM- 1 . This work was supported by Grants-in Aid for Scientific Reseach (No. 61560092) and for Scientific Research on Priority Area of "Macromolecule-Complexes" (No. 62612003) from the Ministry of Education, Science and Culture of Japan.

\section{REFERENCES}

1) K. Ogata, "Ouyo Biseibutsugaku Gairon," Dobunshoin, 1986, p. 89.

2) M. Nagao, M. Suzuki, M. Maruyama and K. Kariyone, Nippon Nōgeikagaku Kaishi, 50, 495 (1976), and references cited therein.

3) M. Ameyama, K. Tayama, E. Shinagawa, K. Matsushita and O. Adachi, Agric. Biol. Chem., 42, 2347 (1978), and references cited therein.

4) Catalogue of Enzymatic Food Analysis, No. 428191, Boehringer-Manheim Yamanouchi Co., 1986 1987.

5) M. A. Jensen and G. A. Rechnitz, J. Membrane Sci., 5, 117 (1979).

6) T. Ikeda, K. Miki, F. Fushimi and M. Senda, Agric. Biol. Chem., 51, 747 (1987).

7) K. Matsushita, E. Shinagawa and M. Ameyama, Methods in Enzymology, 89, 187 (1982).

8) T. Ikeda, H. Hamada, K. Miki and M. Senda, Agric. Biol. Chem., 49, 541 (1985).

9) T. Ikeda, H. Hamada and M. Senda, Agric. Biol. Chem., 50, 883 (1986).

10) M. Senda, T. Ikeda, K. Miki and H. Hiasa, Anal. Sci., 2, 501 (1986).

11) T. Ikeda, K. Miki and M. Senda, Anal. Sci., 4, 133 (1988).

12) T. Ikeda, I. Katasho and M. Senda, Anal. Sci., 1, 455 (1985). 